\title{
Isolation and Identification of Radiation-resistant Cocci Belonging to the Genus Deinococcus from Sewage Sludges and Animal Feeds
}

\author{
Hitoshi Ito, Hiroshi Watanabe, Masaaki TAKehisa \\ and Hiroshi IrzuKA* \\ Takasaki Radiation Chemistry Research Establishment, \\ Japan Atomic Energy Research Institute, \\ Takasaki, Gunma 370-12, Japan \\ *Institute of Applied Biology, Science University of Tokyo, \\ Noda, Chiba 278, Japan
}

Received August 9, 1982

\begin{abstract}
Six strains of radiation-resistant gram-positive cocci were isolated from sewage sludges and animal feeds in Japan after gamma-irradiation of more than $1.0 \mathrm{Mrad}$. All six strains were able to grow on nutrient agar slants, and some strains were also able to grow on glutamate agar slants. Cells of the six strains were single or diplococci, and occasionally seen in tetrads, being spheres averaging from 0.8 to $1.0 \mu \mathrm{m}$ in diameter. The peptide subunit of cells of all the strains contained ornithine, and the predominant fatty acid component was a $\mathrm{C}_{16: 1}$. The GC content of the DNA of these strains ranged from 59 to $66 \mathrm{~mol} \%$ thus indicating them as belonging to the genus Deinococcus Brooks and Murray 1981 which was previously called the "Micrococcus radiodurans" group. From the similar cultural characteristics and morphology, the six strains, TD1, TD3, TD9, T843, Fr 3 and Fr 7, were identified as D. proteolyticus. However, the predominant component of cellular fatty acids of strain T843 was similar to that of D. radiodurans.

The resistance to gamma-radiation of these new isolates was similar to that of $D$. radiodurans $R_{1}$, and $D_{10}$ values in phosphate buffer ranged from 0.10 to $0.25 \mathrm{Mrad}$, and the low oxygen enhancement effect caused by radiation was distinct from other kinds of bacteria.
\end{abstract}

Recent taxonomic studies suggest that the radiation-resistant, red pigmented, catalasepositive cocci are distinct from conventional Micrococcus species. ${ }^{1,2}$ Schleifer and Kandler reported $^{1)}$ that the peptidoglycan in the cell wall contains a unique ornithine subunit, and the occurrence of a significant amount of a lipoprotein-polysaccharide complex on the outermost layer of "Micrococcus radiodurans" resembles that of gram-negative bacteria. Furthermore, the predominant fatty acid in lipid extracts of cells contained a $\mathrm{C}_{16: 1}$ component, and it was also reported by Girard ${ }^{2)}$ that this characteristic resembles that of gramnegative bacteria. From most of the detailed studies of described species of radiationresistant cocci, the new generic name Deinococcus in the new family of Deinococcaceae was proposed by Brooks and
Murray for these bacteria. ${ }^{3)}$ In a previous study, radiation-resistant cocci from sawdust culture media of mushrooms were isolated by Ito, and identified as "Micrococcus radiodurans." ${ }^{4)}$ Recently we also isolated a socalled radiation-resistant red Micrococcus from sewage sludges ${ }^{5}$ and mixed animal feeds ${ }^{6)}$ after gamma-irradiation of more than 1 Mrad. All of these isolates were able to grow on nutrient agar, and sometimes they constituted the main residual flora of sewage sludges in winter and mixed animal feeds after high dose irradiation.

The present work describes isolation, identification and radiation-resistivities of typical isolates from sewage sludges and animal feeds after irradiation. All of the isolates belong to the genus Deinococcus and were identified as Deinococcus proteolyticus. 


\section{MATERIALS AND METHODS}

1. Bacterial strains. Three strains, TD1, TD3 and TD9, were isolated from digested sewage sludge in the winter after gamma-irradiation at 2 Mrad. Strain T843 was isolated from activated sewage sludge in the spring after gamma-irradiation at 1.4 Mrad. Strains Fr3 and Fr7 were isolated from different kinds of mixed animal feeds after gamma-irradiation at 1 Mrad. Strains H48, H54 and $\mathrm{H} 55$ of " $M$. radiodurans" isolated from sawdust culture media were also used for comparison. ${ }^{4)}$ Strains of Deinococcus radiodurans $\mathrm{R}_{1},{ }^{7)}$ Deinococcus radiophilus CCM 2564, ${ }^{8)}$ Deinococcus proteolyticus CCM 2703 ${ }^{9)}$ and Micrococcus roseus IFO 3764 were used for comparative purposes throughout the present investigation. These cultures were grown at $30^{\circ} \mathrm{C}$ on Difco-nutrient agar or PGYM agar containing $10 \mathrm{~g}$ of peptone, $2 \mathrm{~g}$ of glucose, $4 \mathrm{~g}$ of yeast extract, $10 \mathrm{~g}$ of meat extract, $2 \mathrm{~g}$ of sodium chloride and $20 \mathrm{~g}$ of agar per liter.

2. Determination of taxonomic characteristics. A taxonomic study of these isolates was carried out mainly by the method of Cowan and Steel ${ }^{10}$ and identification was done in accordance with Bergey's Manual of Determinative Bacteriology, 8th Ed., ${ }^{11)}$ and with the description of the taxa of Deinococcus provided by Brooks and Murray. ${ }^{3)}$ In addition, glutamate agar containing $5 \mathrm{~g}$ of sodium glutamate, $10 \mathrm{~g}$ of glucose, $1 \mathrm{~g}$ of $\mathrm{K}_{2} \mathrm{HPO}_{4}, 0.1 \mathrm{~g}$ of $\mathrm{KCl}, 0.01 \mathrm{~g}$ of $\mathrm{FeSO}_{4}$ and $20 \mathrm{~g}$ of agar per liter was used for the study of cultural characteristics. For the study of taxonomic characteristics of nutritionally fastidious strains, $0.1 \%$ yeast extract was added to each test medium.

Determination of the base composition of DNA by $T_{\mathrm{m}}$ and principal amino acids in the peptidoglycan were determined by the same method as described previously. ${ }^{4)}$

The predominant cellular fatty acid component was determined by gas chromatography using a $3 \mathrm{~m}$ glass column of $15 \%$ diethyleneglycol succinate coated on $80 /$ 100 mesh Chromosorb GAW in an isothermal run at $200^{\circ} \mathrm{C}$. The samples for gas chromatography were prepared by the method reported by Nishimura et al. ${ }^{12)}$

3. Radiation sensitivity. Pure cultures of each strain were grown for $40 \mathrm{hr}$ in PGYM broth under constant aeration at $30^{\circ} \mathrm{C}$. Cells at the stationary phase were harvested, washed twice with $0.067 \mathrm{M}$ phosphate buffer, $\mathrm{pH} \mathrm{7,} \mathrm{and} \mathrm{then} \mathrm{resuspended} \mathrm{in} \mathrm{the} \mathrm{same} \mathrm{buffer.} \mathrm{These}$ suspensions concentrated to about $1 \times 10^{8}$ cells $/ \mathrm{ml}$ were irradiated at $c a .25^{\circ} \mathrm{C}$ in equilibrium with atmospheric air $(1.5 \mathrm{ml} / 1.5 \mathrm{~cm} \phi$ tube $)$ or under bubbling with air through a capillary tube. Estimation of viable cell counts and dose rate measurements were carried out as described in previous papers. ${ }^{4,13)}$

4. Measurement of catalase activity. Stationary phase cells of each strain incubated for $40 \mathrm{hr}$ were collected and washed twice with distilled water, and lyophilized.
Catalase activity was measured by the method reported in the previous report. ${ }^{13)}$

\section{RESULTS}

\section{Taxonomic characteristics}

All of the isolates from sewage sludges and animal feeds were gram-positive, occurring as single or diplococci or tetrads. As shown in Fig. 1, cells of TD1 and Fr3 were diplococci, and occasionally formed tetrads morphologically resembling the $\mathrm{R}_{1}$ strain of $D$. radiodurans, and strains TD3, TD9 and Fr7 tended to form diplococci similarly to $D$. proteolyticus. However, the cells of T843 occurred singly, and occasionally as diplococci. Cell sizes of all isolates were in the range of 0.8 to $1.0 \mu \mathrm{m}$ which is smaller than that of $D$. radiodurans $\mathrm{R}_{1}$. These six isolates were able to grow on nutrient agar slants, and this characteristic is distinct from $D$. radiodurans $\mathrm{R}_{1}$ and D. radiophilus CCM 2564 as shown in Table $\mathrm{I}$, and also distinct from $\mathrm{H} 48, \mathrm{H} 54$ and $\mathrm{H} 55 .{ }^{4)}$ Strains TD1 and Fr7 were also able to grow on glutamate agar without a growth factor as well as $M$. roseus. All of these strains were strictly aerobic, oxidase-positive, catalase-positive and nonmotile, and some strains produced acids from sugars. The colonies of strains TD3, TD9 and Fr3 on nutrient agar plates after 3 days' incubation at $30^{\circ} \mathrm{C}$ were smooth, mucoid, raised and pale orange to orange in color. However, the color of T843 was white on nutrient agar, and that of TD1 and Fr3 was red as compared with the pink color of $D$. proteolyticus CCM 2703. On the other hand, the color of colonies of all isolates on PGYM agar plates was pale pink to orange red similar to that of $D$. radiodurans and other described species. A small amount of all strains from the agar slants gave a blue color reaction with concentrated sulphuric acid which should indicate the presence of carotenoid-like pigments in the cells. ${ }^{4)}$ Hydrolysis of gelatin and casein were observed in all of strains as well as other radiation-resistant cocci, and these characteristics are distinct from $M$. roseus. All six strains were able to grow on $c a .1 \% \mathrm{NaCl}$ in media 

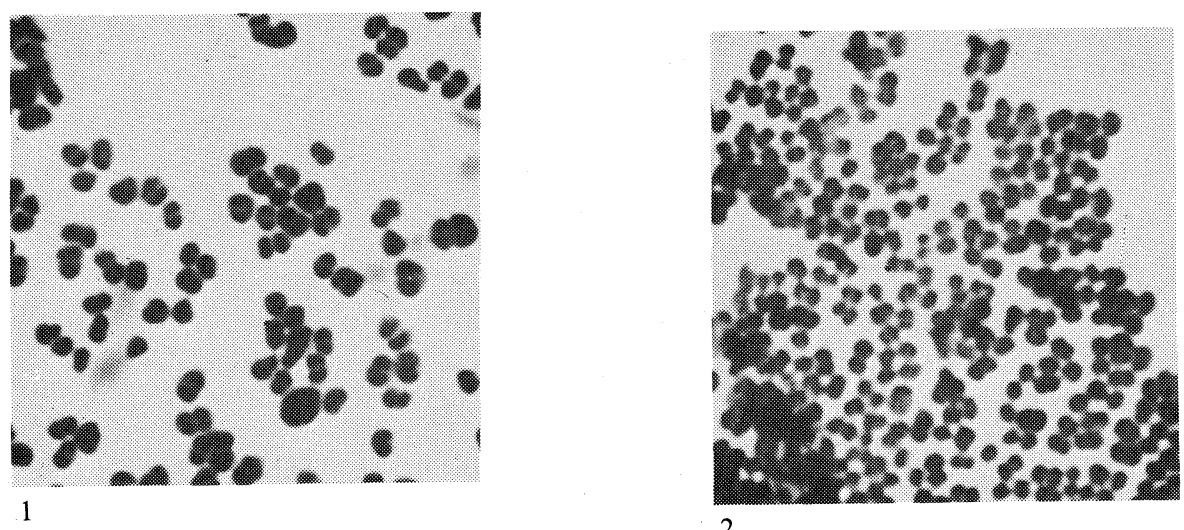

2
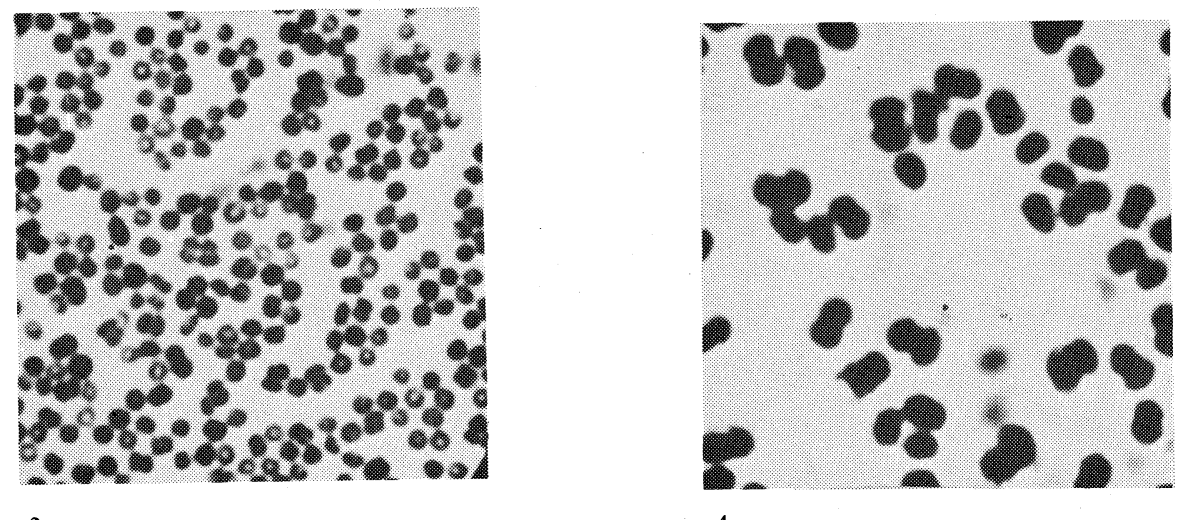

3

4

FIG. 1. Phase Photomicrographs of Radiation-resistant Micrococci at the Exponential Phase of Growth on PGYM Agar. $\times 1500$

1, strain TD1; 2, strain TD3; 3, strain T843; 4, D. radiodurans $\mathbf{R}_{1}$.

and could not grow at $3 \% \mathrm{NaCl}$ in media which is a similar characteristic to that of $D$. radiodurans $\mathrm{R}_{1}$. Cells were resistant against lysis by lysozyme of all isolates, and they were lysed easily with the lytic enzyme of so-called "Achromobacter lunatus"4,14) as well as other radiation-resistant cocci as shown in Table II.

Major amino acids found in the cell walls of the six isolates on paper chromatograms in a solvent system of phenol-water $(7: 3, \mathrm{v} / \mathrm{v})$ are given in Fig. 2 with other described strains. The presence of ornithine, glycine, glutamic acid and alanine as main components of amino acids in peptidoglycan seems to justify identification of these six isolates as the same group of
D. radiodurans. The predominant fatty acid compositions in lipid extracts of cells from these six isolates and three isolates from sawdust culture media indicated that these isolates can be divided into two clusters (Table III and Fig. 3). The predominant fatty acid of TD1, TD3, TD9, Fr3, Fr7, H48, D. proteolyticus CCM 2703 and D. radiophilus CCM 2564 was a $\mathrm{C}_{16: 1}$ component, and large amount of $\mathrm{C}_{15: 1}$ and $\mathrm{C}_{16: 1}$ were observed in strains of T843, H54, H55 and D. radiodurans $R_{1}$. The GC content of DNA of all these strains ranged from 59 to $66 \mathrm{~mol} \%$ by $T_{\mathrm{m}}$ as shown in Table II, and these contents are lower than that of the strains of the genus Micrococcus. 
Table I. Morphological and Cultural Characteristics of Radiation-Resistant Cocci

\begin{tabular}{|c|c|c|c|c|c|c|c|c|c|c|}
\hline & TD1 & TD3 & TD9 & T843 & Fr3 & Fr7 & $\begin{array}{c}\text { D. radiodurans } \\
\mathrm{R}_{1}\end{array}$ & $\begin{array}{l}\text { D. radiophilus } \\
\text { CCM } 2564\end{array}$ & $\begin{array}{l}\text { D. proteolyticus } \\
\text { CCM } 2703\end{array}$ & $\begin{array}{l}\text { M. roseus } \\
\text { IFO } 3764\end{array}$ \\
\hline Morphology of cells & $\begin{array}{l}\text { Diplo } \\
\text { or tetra }\end{array}$ & Diplo & Diplo & $\begin{array}{l}\text { Single } \\
\text { or diplo }\end{array}$ & $\begin{array}{l}\text { Diplo } \\
\text { or tetra }\end{array}$ & Diplo & $\begin{array}{l}\text { Diplo } \\
\quad \text { or tetra }\end{array}$ & $\begin{array}{l}\text { Diplo } \\
\quad \text { or tetra }\end{array}$ & Diplo & $\begin{array}{l}\text { Single } \\
\quad \text { or diplo }\end{array}$ \\
\hline Cell size $(\mu \mathrm{m})$ & $0.8 \sim 1.0$ & 0.8 & $0.8 \sim 1.0$ & $0.8 \sim 1.0$ & $0.8 \sim 1.0$ & 0.8 & $1.0 \sim 2.0$ & 0.8 & $0.8 \sim 1.0$ & $0.6 \sim 0.8$ \\
\hline $\begin{array}{l}\text { Color of colonies } \\
\text { on nutrient agar }\end{array}$ & Red & Orange & $\begin{array}{l}\text { Pale } \\
\text { orange }\end{array}$ & White & Red & $\begin{array}{l}\text { Pale } \\
\text { orange }\end{array}$ & $x$ & $x$ & Pink & Pink \\
\hline Growth on nutrient agar & + & + & + & + & + & + & - & - & + & + \\
\hline Growth on glutamate agar & + & - & - & - & - & + & - & - & - & + \\
\hline Growth at $1 \% \mathrm{NaCl}$ & + & + & + & \pm & + & + & + & + & + & + \\
\hline Growth at $3 \% \mathrm{NaCl}$ & - & - & - & - & - & - & - & + & + & + \\
\hline
\end{tabular}

Diplo, diplococci; tetra, tetrads; $\times$, could not be observed. 
Table II. Biochemical Characteristics of Radiation-Resistant Cocci

\begin{tabular}{|c|c|c|c|c|c|c|c|c|c|c|}
\hline & TD1 & TD3 & TD9 & T843 & Fr3 & Fr7 & $\begin{array}{l}\text { D. radiodurans } \\
\mathrm{R}_{1}\end{array}$ & $\begin{array}{l}\text { D. radiophilus } \\
\text { CCM2564 }\end{array}$ & $\begin{array}{l}\text { D. proteolyticus } \\
\text { CCM2703 }\end{array}$ & $\begin{array}{l}\text { M. roseus } \\
\text { IFO } 3754\end{array}$ \\
\hline Gelatin liquefaction & ++ & + & + & +++ & ++ & + & + & ++ & ++ & - \\
\hline Hydrolysis of casein & +++ & ++ & ++ & ++ & ++ & +++ & ++ & ++ & ++ & - \\
\hline $\mathrm{NO}_{3}$ reduction & - & - & +++ & - & - & +++ & - & - & - & - \\
\hline Hydrolysis of fats & + & - & - & + & + & - & - & - & - & - \\
\hline $\begin{array}{l}\text { Growth with novobiocin } \\
\quad 0.6 \mu \mathrm{g} / \mathrm{ml}\end{array}$ & - & - & - & - & - & - & - & - & - & - \\
\hline Production of acid & & & & & & & & & & \\
\hline from glucose & - & - & + & + & - & - & + & + & + & + \\
\hline xylose & - & - & - & - & - & - & - & - & - & - \\
\hline sucrose & + & - & + & + & - & + & + & - & + & + \\
\hline $\begin{array}{l}\text { Lysis of cells by } \\
\text { lysozyme }\end{array}$ & - & - & - & + & - & + & - & ++ & - & - \\
\hline $\begin{array}{l}\text { lytic enzyme of } \\
\text { "A. lunatus" } 14)\end{array}$ & + & ++ & ++ & +++ & + & ++ & ++ & +++ & ++ & - \\
\hline Oxidase & +++ & +++ & +++ & +++ & +++ & +++ & +++ & +++ & +++ & ++ \\
\hline $\begin{array}{l}\text { Catalase } \\
\text { GC content of DNA }(\%)\end{array}$ & $\begin{array}{c}+++ \\
64\end{array}$ & $\begin{array}{c}+++ \\
66\end{array}$ & $\begin{array}{c}++ \\
62\end{array}$ & $\begin{array}{c}+++ \\
59\end{array}$ & $\begin{array}{c}+++ \\
62\end{array}$ & $\begin{array}{l}+ \\
62\end{array}$ & $\begin{array}{c}+++ \\
66\end{array}$ & $\begin{array}{c}+++ \\
61\end{array}$ & $\begin{array}{c}+++ \\
65\end{array}$ & $\begin{array}{l}+++ \\
66 \sim 74^{a}\end{array}$ \\
\hline
\end{tabular}

+++ , strong; ++ , moderate; + , weak; - , negative.

a Values for M. roseus, with reference to Bergey's Manual of Determinative Bacteriology, 8th Ed. ${ }^{11)}$ 
From these results, all radiation-resistant cocci are distinct from conventional Micrococcus species, and they should be included in the genus Deinococcus recently proposed by Brooks and Murray (1981). Here, all strains, TD1, TD3, TD9, T843, Fr3 and Fr7, should be identified as D. proteolyticus, which was formerly known as "Micrococcus radioproteolyticus" isolated by Kobatake et al., ${ }^{9)}$ on the basis of the similar cell morphology and ability to grow on nutrient agar. However,

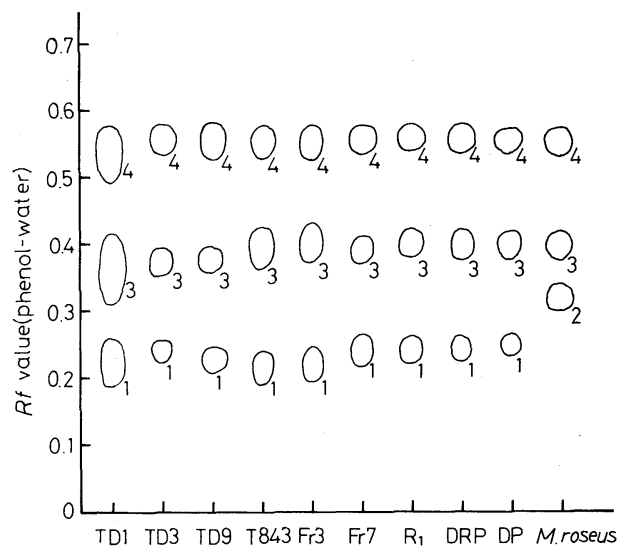

FIG. 2. Paper Chromatograms of Acid Hydrolysates $\left(6 \mathrm{~N} \mathrm{HCl}, 100^{\circ} \mathrm{C}, 8 \mathrm{hr}\right)$ of Cell Walls of Radiation-resistant Micrococci Developed with Ninhydrin.

$\mathrm{R}_{1}$, D. radiodurans $\mathrm{R}_{1}$; DRP, D. radiophilus CCM 2564; DP, D. proteolyticus CCM 2703. 1, ornithine; 2, lysine; 3, glycine and glutamic acid; 4 , alanine. these six strains could not grow at $3 \% \mathrm{NaCl}$ compared with strains CCM 2703, and TD9 and Fr7 had the ability to reduce nitrates to nitrites. In the case of strain T843, its predominant fatty acids were $\mathrm{C}_{15: 1}$ and $\mathrm{C}_{16: 1}$ similar to $D$. radiodurans $\mathrm{R}_{1}$, whereas characteristics of occurring singly or in pairs, small cell size, white to pale pink colonies, $59 \% \mathrm{GC}$ content of DNA and ability to grow on nutrient agar are distinct from those of $D$. radiodurans. On the other hand, isolates $\mathrm{H} 54$ and H55 from sawdust culture media should be classified as $D$. radiodurans from the similar

Table III. Composition of Predominant Cellular Fatty Acids of RadiationRESISTANT COCCI

\begin{tabular}{lrc}
\hline \multirow{2}{*}{ Strain } & \multicolumn{2}{c}{ Fatty acids (\%) } \\
\cline { 2 - 3 } & $\mathrm{C}_{15: 1}$ & $\mathrm{C}_{16: 1}$ \\
\hline TD1 & 10 & 80 \\
TD3 & 10 & 83 \\
TD9 & 12 & 82 \\
T843 & 42 & 50 \\
Fr3 & 10 & 80 \\
Fr7 & 8 & 85 \\
H48 & 12 & 78 \\
H54 & 36 & 55 \\
H55 & 40 & 52 \\
D. radiodurans R $_{1}$ & 40 & 51 \\
D. radiophilus CCM2564 & 6 & 80 \\
D. proteolyticus CCM2703 & 5 & 80 \\
\hline
\end{tabular}

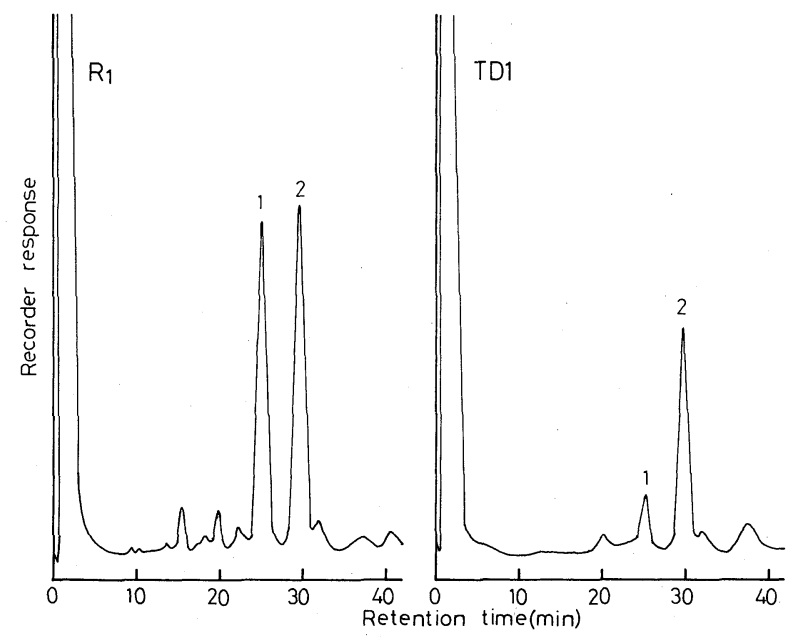

FIG. 3. Gas Chromatogram of Cellular Fatty Acids of D. radiodurans $\mathbf{R}_{1}$ and Strain TD1. $1, \mathrm{C}_{15: 1} ; 2, \mathrm{C}_{16: 1}$. 
Table IV. Comparative Radiation Sensitivities of the Strains of Deinococcus and Their Catalase Activities

\begin{tabular}{lcccc}
\hline \multirow{2}{*}{ Strain } & \multicolumn{2}{c}{$\mathrm{D}_{10}$ value (Mrad) with the condition of } & $\begin{array}{c}\text { Oxygen } \\
\text { enhancement } \\
\text { value }\end{array}$ & $\begin{array}{c}\text { Catalase } \\
\text { activity } \\
\text { Kat. } f\end{array}$ \\
\cline { 2 - 3 } Air-bubbling & Air-equilibrium & & 99.9 \\
TD1 & 0.20 & 0.20 & 1.0 & 90.7 \\
TD3 & 0.10 & 0.15 & 1.5 & 84.4 \\
T843 & 0.18 & 0.20 & 1.1 & 201.3 \\
Fr3 & 0.18 & 0.20 & 1.1 & 78.6 \\
Fr7 & 0.13 & 0.17 & 1.3 & 2.1 \\
H48 & 0.11 & 0.11 & 1.0 & 23.7 \\
H54 & 0.19 & 0.22 & 1.2 & 13.6 \\
H55 & 0.19 & 0.19 & 1.0 & 38.0 \\
D. radiodurans $\mathrm{R}_{1}$ & 0.22 & 0.22 & 1.2 & 140.4 \\
D. radiophilus CCM2564 & 0.21 & 0.25 & 1.1 & 81.0 \\
D. proteolyticus CCM2703 & 0.22 & 0.24 & 1.0 & 217.2 \\
M. roseus IFO 3764 & 0.34 & 0.34 & 2.0 & 95.5 \\
\hline
\end{tabular}

predominant fatty acid components and other similar characteristics as described in the previous report. ${ }^{4)}$ However, strain $\mathrm{H} 48$ should be reidentified as $D$. radiophilus from the predominant fatty acid, $\mathrm{C}_{16: 1}$, small cell size, and similar growth characteristics such as the ability to grow at $3 \% \mathrm{NaCl}$.

\section{Radiation-resistivity}

The resistance to gamma-radiation of these isolates from sewage sludges ${ }^{5)}$ and animal feeds $^{6)}$ was similar to that of $D$. radiodurans $R_{1}$ and other described species, and $D_{10}$ values ranged from 0.10 to $0.25 \mathrm{Mrad}$ in the aerobic irradiation conditions as shown in Table IV. However, the shape of survival curves was distinct for each strain, and many strains showed sigmoidal curves with different sized shoulders (Fig. 4). On the other hand, the shape of the survival curves of TD1 and $D$. proteolyticus CCM 2703 were exponential and this is not related to the morphology of diplococci or tetrads at the stationary phase of growth. The $\mathrm{D}_{10}$ values of each strain with the condition of air-equilibrium are almost the same as those with nitrogen gas equilibrium and this anaerobic condition could be attained after irradiation of more than $0.3 \mathrm{Mrad}$ by consumption of oxygen. The oxygen enhancement ratio of all radiation-resistant cocci $\left(D_{10}\right.$ of anaerobic condition $/ \mathrm{D}_{10}$ of air-bubbling) ranged from 1.0 to 1.5 as shown in Table IV, and these results show that the oxygen enhancement effect is not important for the radiation sensitivity of the strains of the genus Deinococcus. For example, the survival curve of TD1 obtained after irradiation with the condition of air-bubbling, air-equilibrium and nitrogen gas equilibrium showed the same $D_{10}$ value and the same exponential curve, and these results are very distinct from other kinds of bacteria such as Pseudomonas radiora ${ }^{13)}$ and Escherichia coli. ${ }^{15)}$

Catalase activity as shown by Kat. $f$ for each strain was distributed from 2 to 212 indicating that the catalase activity is not related to the oxygen enhancement ratio and radiationresistance for each strain of Deinococcus. This result is also very distinct from that of $P$. radiora in which catalase activity correlated with the oxygen effect as reported in the previous paper. ${ }^{13)}$

\section{Description}

The detailed characteristics of the six isolates from sewage sludges and animal feeds are as follows.

Deinococcus proteolyticus Brooks and Murray 1981.

Strains: TD1, TD3, TD9, T843, Fr3, Fr7 

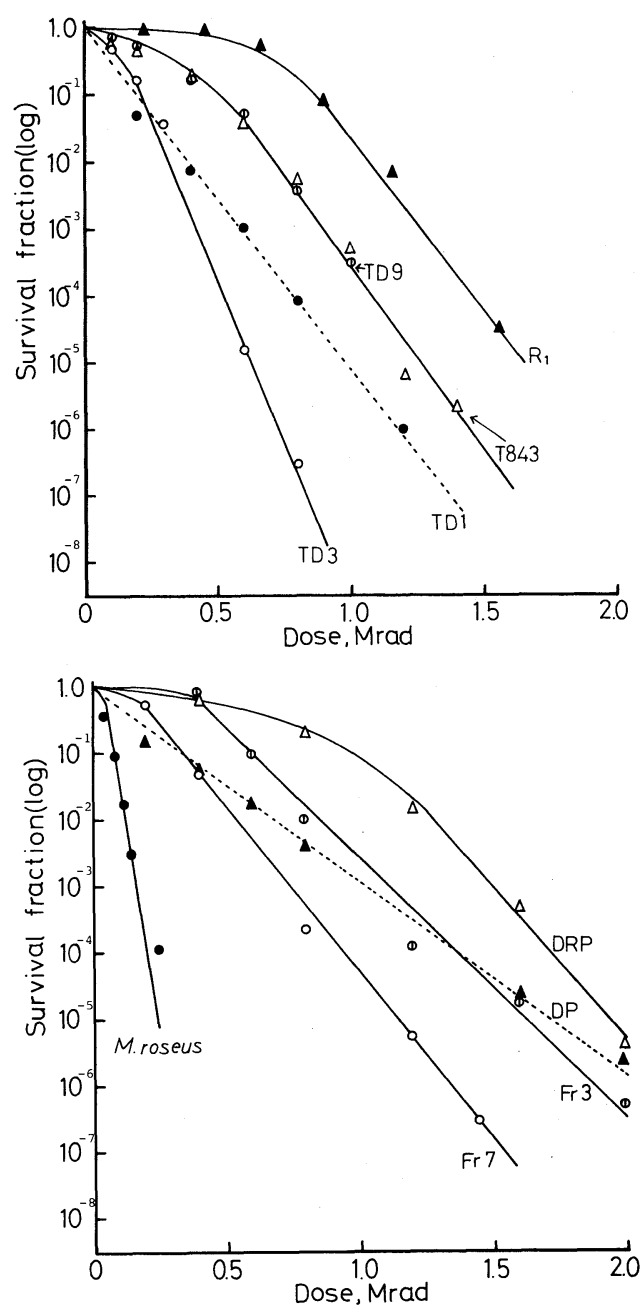

FIG. 4. Comparative Sensitivities of Several Strains of Radiation-resistant Micrococci to Gamma Irradiation under Air-bubbling in Phosphate Buffer.

$\mathrm{R}_{1}$, D. radiodurans $\mathrm{R}_{1}$; DRP, D. radiophilus CCM 2564; DP, D. proteolyticus CCM 2703.

Spheres, 0.8 to $1.0 \mu \mathrm{m}$ in diameter, occurring singly or in pairs and sometimes dividing in two planes to form tetrads. Non-motile.

The peptide subunit of the cell wall contains ornithine. The predominant fatty acid component is $\mathrm{C}_{16: 1}$. No branched fatty acids are present.

Colonies on nutrient agar are generally orange to red and some strains are white to pink, smooth, and convex with a regular edge.

Chemoorganotrophic; metabolism is respiratory. Acid without gas is produced from glucose and sucrose when attacked. Casein and gelatin are hydrolyzed. Nitrates are reduced to nitrites or not reduced.

Strictly aerobic. Growth in the presence of $1 \% \mathrm{NaCl}$, but can not grow at $3 \% \mathrm{NaCl}$. Grow on nutrient agar without other growth factors.

Cytochrome oxidase and catalase positive.

The GC content of DNA is $59 \sim 66 \mathrm{~mol} \%$ (by $T_{\mathrm{m}}$ ).

Source: Sewage sludges and animal feeds after high dose gamma-ray irradiation.

\section{DISCUSSION}

Radiation-resistant cocci which belong to the genus Deinococcus recently proposed by Brooks and Murray ${ }^{3)}$ can be found in broad environments in Japan such as in sewage sludges, ${ }^{5)}$ mixed animal feeds, ${ }^{6}$ ) and other sources $^{4,9)}$ after irradiation at high doses. In this study, all isolates were able to grow on nutrient agar, and this characteristic was distinct from that of the type strain of $D$. radiodurans. One of the problems in defining Deinococcus species is that all the described strains were obtained with radiation as the selective factor, and there is a possibility of nutritional mutations occurring after irradiation. However, all of the isolates in this study seem to have wild type characteristics even after irradiation similar to other bacteria which can be identified as described species. $^{5,6,13)}$ For this reason, it is supposed that the nutritional requirement is also important for taxonomical classification. Therefore, isolates TD1, TD3, TD9, T843, Fr3 and Fr7 were identified as D. proteolyticus. However, they had some different characteristics compared with type strain CCM 2703. Furthermore, strain T843 had different characteristics compared with the other five strains, and it is not considered to be a typical D. proteolyticus. In the case of isolates from sawdust culture media, $\mathrm{H} 54$ and $\mathrm{H} 55$ were confirmed to belong to $D$. radiodurans as in the previous report. ${ }^{4)}$ Whereas, $\mathrm{H} 48$ should be reidentified as $D$. radiophilus on the basis of its fastidious nutritional require- 
ments and higher salt tolerance compared with other isolates. In this study, all Deinococcus strains showed radiation-resistance and a low oxygen enhancement effect, and these radiation effects are also important characteristics of the genus Deinococcus.

Further studies are needed on the taxonomic relation between the genera Deinococcus and Micrococcus, and among all Deinococcus isolates using methods such as DNA homology and interspecies transformation.

Acknowledgment. The authors wish to thank Mr. T. Kume for his helpful discussions during the course of this investigation.

\section{REFERENCES}

1) K. H. Schleifer and O. Kandler, Bacteriol. Rev., 36, 407 (1972).

2) A. E. Girard, Can. J. Microbiol., 17, 1503 (1971).

3) B. W. Brooks and R. G. E. Murray, Int. J. Syst. Bacteriol., 31, 353 (1981).
4) H. Ito, Agric. Biol. Chem., 41, 35 (1977).

5) H. Ito, H. Watanabe, H. Iizuka and M. Takehisa, Agric. Biol. Chem., submitted.

6) H. Ito, T. Kume, M. Takehisa and H. Iizuka, Nippon Nôgeikagaku Kaishi, 55, 1081 (1981).

7) A. W. Anderson, H. C. Nordan, R. F. Cain, G. Parrish and D. Dugan, Food Technol., 10, 575 (1956).

8) N. F. Lewis, J. Gen. Microbiol., 66, 29 (1971).

9) M. Kobatake, S. Tanabe and S. Hasegawa, Compt. Rend. Sean. Soc. Biol., 167, 1506 (1973).

10) S. T. Cowan and K. J. Steel, "Identification of Medical Bacteria," Second Ed., Cambridge University Press, Cambridge, 1974.

11) R. E. Buchanan and N. E. Gibbons (ed.), "Bergey's Manual of Determinative Bacteriology," 8th Ed., Williams and Wilkins, Baltimore 1974, p. 478.

12) Y. Nishimura, H. Yamamoto and H. Iizuka, Zeitschrift für Allgemeine Mikrobiologie, 19, 307 (1979).

13) H. Ito and H. Iizuka, Agric. Biol. Chem., 44, 1315 (1980).

14) H. Watanabe and T. Sato, Agric. Biol. Chem., 45, 1209 (1981).

15) H. P. Misra and I. Fridovich, Arch. Biochem. Biophys., 176, 577 (1976). 